\title{
Model development for the selection of the optimal form of information and consulting service in the agricultural sector of Uzbekistan
}

\author{
Iroda Rustamova $^{1 *}$, Firyuza Galimova ${ }^{1}$, Nilufar Dekhkanova ${ }^{1}$, and Mukhlisa Usmanova $^{2}$ \\ ${ }^{1}$ Tashkent State Agrarian University, 100140 Tashkent province, Uzbekistan \\ ${ }^{2}$ Tashkent Institute of Finance, 100000 Tashkent, Uzbekistan
}

\begin{abstract}
An important condition for the dynamic development of the Republic of Uzbekistan is the accelerated introduction of modern innovative technologies in the economy, social and other spheres with the widespread use of the achievements of science and technology. In order to assess the degree of use of information and consulting services and the application of innovations in farms of the republic, within the framework of the project, a survey of heads of farms was conducted and, on the basis of the survey, a model of the optimal form of information and consulting services for agriculture was developed.
\end{abstract}

\section{Introduction}

According to world experience, the creation, implementation and wide distribution of new products, services and technological processes based on knowledge are becoming an important factor in production, employment and investment, which determines the formation and efficiency of an intensive model of organizing production, increasing labor productivity, saving labor and material costs, improving the quality of products $[1,2]$. A significant factor in the growth of the competitiveness of any country is its gradual transition to an innovative path of development. According to scientists, a key role in solving strategically important problems of various countries in the 21 st century is assigned to a knowledge-based economy, or an innovative economy [3]. Over the past 15 years, the number of people working in the field of innovation in the United States and Western Europe has doubled, and in Southeast Asia - 4 times. The share of innovatively active industrial enterprises in the European Union was over 56 percent. In the developed world, innovation accounts for 75 percent of gross domestic product [4].

In the face of global climate change in the coming decades, the agri-food sector will face a sharp increase in global demand and increased competition for limited natural resources, which will require adaptation to climate change and mitigation of such changes. Innovation, as mentioned, is essential to meet growing demand and to foster the expansion of networks called food systems that integrate sustainable production, processing, distribution and consumption of food and waste management [5]. Scientists estimate that by

* Corresponding author: irodarustamova@mail.ru 
2050 the world's population will reach 9.6 billion people and in order to provide them with food, it will be necessary to increase food production by 60 percent compared to today. Foreign trends show that each year the number of created innovations (recognized in foreign patent offices) per million inhabitants is: in the USA - 261.7; in Japan - 213.0; in Germany - 206.3; in France - 171.9; and, in Russia - 1.3 [6, 7].

Today in Uzbekistan, consistent measures are being implemented to ensure a wider integration of science, education and production, the creation and application of new knowledge, the introduction of innovative technologies and advanced experience [8]. However, the problems that have not been resolved for many years, related to the failure to introduce the processes of introducing innovative technologies and the results of scientific research aimed at the development of the agricultural sector, to the lowest levels of the sphere, hinder the accelerated development of the agricultural sector. In this regard, for the future, as a priority direction for the development of agriculture, "the development of science, education, the system of information and consulting services, providing for the use of effective forms of dissemination of knowledge and information, integrated with production and research, educational and consulting services in agriculture" [9]. This circumstance raises the need to develop scientific and methodological foundations for increasing the efficiency of innovation processes to increase the economic potential of agricultural entities, conducting systemic research on the scientific, theoretical and methodological aspects of these processes.

\section{Materials and methods}

Scientific research related to the creation, development of innovative technologies in agriculture and their adaptation to climate change is carried out and, to a certain extent, achieve positive results by such leading world scientific centers as the Wageningen University and Research Center (WUR), Food and Agriculture Organization United Nations Organization (FAO), International Center for Agricultural Research in the Dry Areas (ICARDA), United Nations Development Program (UNDP), Global Environment Facility (GEF), Korea Agricultural Development Administration (RDA) [10-13].

In the field of integrating science, education and production in higher educational institutions of the world, including the Center for Agricultural Research and Extension of the Pennsylvania Agricultural College (KARE), the Pennsylvania State College of Agricultural Sciences (FRES), proposals and recommendations have been developed for the development of information and consulting services (extension) for the promotion and implementation of innovations for agricultural producers. Methodological recommendations for the creation of innovative technologies in crop production and assessment of the economic efficiency of innovative technologies in agriculture have been developed by the All-Russian Research Institute of Agricultural Economics, the AllRussian Institute of Plant Production [14-16].

At present, world research is being conducted on innovative processes and increasing their efficiency in the agricultural sector in the following areas: improving the mechanisms for the development of the system of science, education, information and consulting services; assessment of the effectiveness of innovative technologies; improvement of the scientific foundations for the development of innovative processes in agriculture [14].

The problems of improving the scientific and methodological foundations for increasing the efficiency of innovation processes in the agricultural sector of the economy have been investigated by such foreign scientists as J.C.Aker, F.C.Anaeto, N.P.Archer, N.S.Bentsen, A.B.Berger, J.N.Binam, B.Griffith, B. Gebremedhin, D.Y.Delong, A.Pakes, J.Putnam, S.Kamiyama, K.Knickel, A.Knierim, P.Labarthe, A.Lopez, B.Livson, D.H.Luthy, J.O.Lanjouw, T.Nguen, P.K.Reddy, M.W.Rosegrant, E.M.Smeets, P.H.Sullivan, 
T.A.Stewart, B.H Hall, T.Hagerstrand, V.Hoffmann, J.Harrington, N.C.Havkins and other. The issues of improving the development of innovative processes in agriculture are widely described in the studies of scientists from the CIS countries V.M. Anyshin, V.G. Andreichuk, A.I. Averkiev, V.M. Bautin, I.V. Gontareva, V.I. Dragaytsev, V. M. Koshelev, L. V. Lyovina [1-9].

The study of the problems of assessing and improving the efficiency of the use of innovations in agriculture is considered in scientific studies of such domestic scientists as U.P. Umurzakov, K.A. Choriev, O. Murtazaev, N.S. Khushmatov, F.T. Egamberdiev, B. T. Salimov, G. A. Samatov, S. R. Umarov, A. Mukhtorov and others [10-19].

It should be noted that the theoretical developments, proposals and recommendations of these scientists are aimed at sustainable development of agriculture, but at the same time, an insufficient level of research based on modern requirements of such issues as increasing the efficiency of innovation processes in the agricultural sector, the activities of information and consulting services, technology parks in the agricultural sector, the mechanisms, methods and ways of introducing and effectively using innovations in agriculture necessitate targeted research in this direction.

\section{Results and discussion}

The effectiveness of the information and consulting service is due to many factors, including the right choice of its organizational and legal form. However, by now there is no sufficient in-depth comparative analysis of various forms of service allowing make reasoned decisions to the Internet Control Service management bodies on the choice of the most appropriate organizational and legal form of regional ICS.

The problem of choosing the organizational and legal forms of ICS is related to the task of decision making in conditions of significant uncertainty. Expert systems based on logical-linguistic or frame models can be used; methods of game and fuzzy sets theory, methods of probability and mathematical statistics theory, etc. can be used here. The conceptual basis for the development should be the methods and mathematical apparatus of modeling system.

It should be mentioned that the activities of ICS, as a business entity depend not only on the form and structure of the organization, which determines the basic properties (parameters) of its behavior and future development, but also on a variety of factors, both internal and external. The internal factors are typical enough for the activity of any business entity and are determined by the real practical approach to the management of the enterprise (management) which are not considered in this work. The remaining characteristics of the system under study, namely, the basic properties (parameters) of the organizational-legal form and a multitude of external factors are extremely important for conducting analytical work and developing methodological materials.

The definition of the problem is presented in the following form. There is an ICS system that includes many regional services of various legal forms or a plurality of objects A, each of which has many parameters that characterize their activity - R. Regional ICSs function in an external environment determined by many factors - X.

In the context of the regional ICS, following the conceptual basis of the development of ICS, it is possible to formulate two main goals of its operation: to provide high-quality information and consulting services and to organize the activities of the regional ICS.

Considering the information and consulting services from the standpoint of the market, a relevance to consumers should be recognized an indirect assessment of the quality and completeness of the services provided. It may be considered that the demand for services is a constant value that significantly exceeds today's supply (even taking into account the fact that the supply is formed not only through the ICS). Then the range of services offered in 
the market of the agro-industrial complex must constantly increase, at least in the initial period of operation of the agro-industrial complex. Therefore, a positive change in the range of services sold can be viewed as an indicator (criterion) of the degree of achievement of the first goal of functioning of the regional ICS. Such a criterion is acceptable at the initial stage of development of the ICS and should be revised in order to achieve stable operation of the ICS. In the future, such a criterion can be the maximum satisfaction of incoming requests to the ICS on problems of the agro-industrial complex or the self-sufficient of the service activities.

From the point of view of the second objective of the functioning of the regional ICS, the criterion should be the functioning quality of the district ICS characterized by the volume of services implemented at the district level.

The defined criteria are contradictory. Indeed, the better the work of the district VIC is organized, the greater the range of services provided at the district level, the smaller the increase of services at the regional level (and vice versa). However, at the initial stage of development of ICS, in the conditions of excessive demand for services, these criteria can be combined and further considered as one indicator - the change in the range of consulting services in the region.

Let's present the efficiency function of the regional ICS activity in the form of some production function of ICS-F, which depends: on the form of the center, on the set of parameters characterizing their activity - $\mathrm{P}$ and on the set of environmental factors - X, i.e. $\mathrm{F}(\mathrm{A}, \mathrm{P}, \mathrm{X})$. The criterion is the maximization of the efficiency function, i.e. - maxF.

On the basis of the above, it is useful to identify three methodological problems of choosing the organizational and legal form of ICS (Table 1).

Task 1 - to determine the optimal organizational and legal form of ICS under the initial (static) state of the external environment (X), and in such a way that the parameters (properties) of the chosen form most satisfy the current state of the external environment which will allow the most efficient use of all existing potential resources of this form in the implementation of the production function of the ICS, i.e. will allow to provide the criterion of the efficiency function. Otherwise, it can be represented as follows:

Organizational and legal form $\rightarrow$ optimum at $\mathrm{P}>\mathrm{X}$.

Task 2 - to determine the optimal organizational and legal form of the current ICS in the current (dynamic) state of the external environment, in such a way that its activity is least dependent on changes in environmental factors - $\mathrm{X}$ in terms of minimizing the possible risks of the production function $\mathrm{X}$. In this case, the private efficiency function can be represented as a certain complex function of the influence of factors $\mathrm{X}$ on the production function, and the criterion is the minimization of this influence function (or check function of stability).

Task 3 is to determine the optimal organizational and legal form for a comprehensive assessment of the creation and operation of a regional SEC, that is, to combine the solutions obtained for the first two tasks into a finally recommended solution.

Below is a solution to these problems.

Consider the following set of objects (organizational and legal forms) - A:

1. A1 - consulting centers at the Council of farmers;

2. A2 - farmer training centers in the university;

3. A3 - information and consultation centers at the Chamber of Commerce and Industry;

4. A4 - Scientific research institutes' departments of agrotechnologies' integration;

5. A5 - extension components of projects of international organizations;

6. A6 - private firms rendering information and consulting services. 
Table 1. Output of the sociological survey on the study of the use of information and consulting services.

\begin{tabular}{|c|c|c|c|c|c|c|c|}
\hline \# & Indicators & 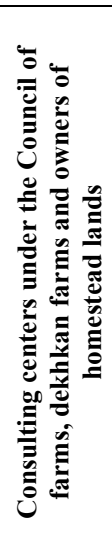 & 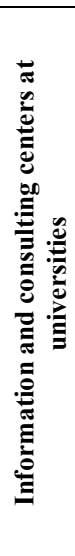 & 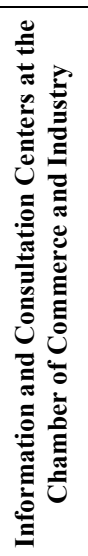 & 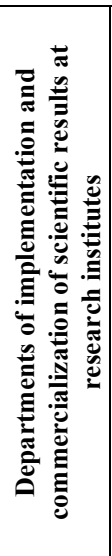 & 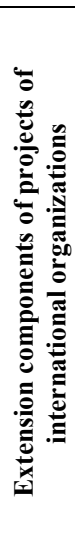 & 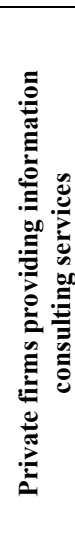 \\
\hline 1 & $\begin{array}{l}\text { The presence and level } \\
\text { of ICS staff training }\end{array}$ & 1 & 2 & 1 & 1 & 0 & 0 \\
\hline 2 & $\begin{array}{l}\text { The degree of budget } \\
\text { financing }\end{array}$ & 0 & 1 & 0 & 2 & 0 & 0 \\
\hline 3 & $\begin{array}{l}\text { Regional policy of the } \\
\text { management of the } \\
\text { agroindustrial complex } \\
\text { to support ICS }\end{array}$ & 2 & 1 & 1 & 1 & 0 & 0 \\
\hline 4 & $\begin{array}{c}\text { The presence of a } \\
\text { competitive environment }\end{array}$ & 1 & 1 & 1 & 1 & 1 & 0 \\
\hline 5 & $\begin{array}{c}\text { The financial situation of } \\
\text { consumers of ICS } \\
\text { services }\end{array}$ & 1 & 0 & 1 & 1 & 2 & 0 \\
\hline 6 & $\begin{array}{l}\text { Readiness of consumers } \\
\text { to contact ICS }\end{array}$ & 2 & 2 & 2 & 2 & 0 & 2 \\
\hline 7 & $\begin{array}{c}\text { Readiness of the ICS to } \\
\text { provide a variety of } \\
\text { services }\end{array}$ & 1 & 2 & 1 & 2 & 0 & 0 \\
\hline
\end{tabular}

We formulate a matrix of values of the parameters $[\mathrm{P}]$ for each form, in the generally consisting of $\mathbf{m}$ parameters:

$\begin{array}{lllllll} & & p 1 & p 2 & p 3 & \ldots & p m \\ & & \downarrow & \downarrow & \downarrow & & \downarrow \\ A 1 & \rightarrow & p 11 & p 12 & p 13 & \ldots & p 1 m \\ A 2 & \rightarrow & p 21 & p 22 & p 23 & \ldots & p 2 m \\ A 3 & \rightarrow & p 31 & p 32 & p 33 & \ldots & p 3 m \\ A 4 & \rightarrow & p 41 & p 43 & p 43 & \ldots & p 4 m \\ A 5 & \rightarrow & p 51 & p 52 & p 53 & \ldots & p 5 m \\ A 6 & \rightarrow & p 61 & p 62 & p 63 & \ldots & p 6 m\end{array}$

The current situation of the external environment, characterized by $\mathrm{n}$ factors, we

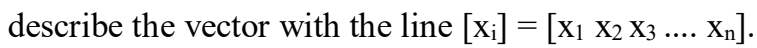

We single out such parameters of the organizational and legal forms of objects that would fully correspond to environmental factors in terms of quantity and in essence, that is:

$\mathrm{m}=\mathrm{n}$ and $\mathrm{p}_{\mathrm{i}}=\mathrm{x}_{\mathrm{i}}$

In particular, we set $\mathrm{m}=\mathrm{n}=7$, and:

$\mathrm{p}_{1}=\mathrm{x}_{1}$ - the presence and level of ICS staff training

$\mathrm{p}_{2}=\mathrm{x}_{2}$ - the degree of budget financing, 

ICS,

$\mathrm{p}_{3}=\mathrm{x}_{3}$ - regional policy of the management of the agroindustrial complex to support

$\mathrm{p}_{4}=\mathrm{x}_{4}$ - the presence of a competitive environment $\mathrm{X}$,

$\mathrm{p}_{5}=\mathrm{x}_{5}$ - the financial situation of consumers of ICS services,

$\mathrm{p}_{6}=\mathrm{x}_{6}-$ readiness of consumers to contact ICS,

$\mathrm{p}_{7}=\mathrm{x}_{7}-$ readiness of the ICS to provide a variety of services.

Evaluation of parameters and factors should be carried out expertly on a 3-point scale, which is much simpler (for example: dissatisfaction, satisfactory, good). In this case, the technique of expert analysis may be as follows:

The question given in the questionnaire on the first parameter of the form asks:

Assess the property (parameter) of p1 - "the capacity to select and prepare frames for various forms of X" (check the corresponding box with a plus sign) on a three-point scale:

$A 1$
$A 2$
$A 3$
$A 4$
$A 5$
$A 6$
low average high

Similarly, a questionnaire is compiled to evaluate the remaining parameters.

As an example, we will make an expert assessment of the parameters of the organizational and legal form:

1. The ability to select and prepare personnel for the ICS:

$\begin{array}{ll}\text { A1-average- } & 1 \\ \text { A2- high- } & 2 \\ \text { A3- average- } & 1 \\ \text { A4- average- } & 1 \\ \text { A5-low- } & 0 \\ \text { A6-low- } & 0\end{array}$

2. Dependence on budget financing of ICS activity:

$\begin{array}{ll}\text { A1-low- } & 0 \\ \text { A2-average- } & 1 \\ \text { A3-low- } & 0 \\ \text { A4-high- } & 2 \\ \text { A5-low- } & 0 \\ \text { A6-low- } & 0\end{array}$

3. Activities dependence on the regional policy of the agro-industrial complex management in support of ICS:

$\begin{array}{ll}\text { A1-high- } & 2 \\ \text { A2-average- } & 1 \\ \text { A3-average- } & 1 \\ \text { A4-average- } & 1 \\ \text { A5-low- } & 0 \\ \text { A6-low- } & 0\end{array}$

4. The degree of independence of activity from the presence of competitors in the environment of the ICS:

$\begin{array}{ll}\text { A1-average- } & 1 \\ \text { A2-low- } & 0 \\ \text { A3- average- } & 1 \\ \text { A4- average- } & 1 \\ \text { A5- high- } & 2 \\ \text { A6- low- } & 0\end{array}$

5. The degree of independence of activity from the financial situation of consumers of ICS: 


$\begin{array}{ll}A_{2}-\text { low - } & 0 \\ A_{3}-\text { average- } & 1 \\ A_{4}-\text { average- } & 1 \\ A_{5}-\text { high }- & 2 \\ A_{6}-\text { low }- & 0\end{array}$

6. Dependence of activity on consumer readiness to contact ICS:

$\begin{array}{ll}\text { A1- high- } & 2 \\ A_{2}-\text { high- } & 2 \\ A_{3} \text { high- } & 2 \\ A_{4}-\text { high }- & 2 \\ A_{5}-\text { low- } & 0 \\ A_{6}-\text { high }- & 2\end{array}$

7. ICS readiness to provide a variety of services:

$\begin{array}{ll}\text { Al- average- } & 1 \\ A_{2} \text { high- } & 2 \\ A_{3} \text {-average- } & 1 \\ A_{4} \text { high }- & 2 \\ A_{5}-\text { low }- & 0 \\ A_{6}-l o w- & 0\end{array}$

As a result, we obtain a numerical matrix $\mathrm{P}(7 \times 7)$ with the assigned values of its elements according to the answers of the expert:

$\begin{array}{lllllllll} & & p_{1} & p_{2} & p_{3} & p_{4} & p_{5} & p_{6} & p_{7} \\ & & \downarrow & \downarrow & \downarrow & \downarrow & \downarrow & \downarrow & \downarrow \\ A_{1} & \rightarrow & 1 & 0 & 2 & 1 & 1 & 2 & 1 \\ A_{2} & \rightarrow & 2 & 1 & 1 & 1 & 0 & 2 & 2 \\ A_{3} & \rightarrow & 1 & 0 & 1 & 1 & 1 & 2 & 1 \\ A_{4} & \rightarrow & 1 & 2 & 1 & 1 & 1 & 2 & 2 \\ A_{5} & \rightarrow & 0 & 0 & 0 & 1 & 2 & 0 & 0 \\ A_{6} & \rightarrow & 0 & 0 & 0 & 0 & 0 & 2 & 0\end{array}$

To increase the results representativeness, it is advisable to produce a mass questionnaire survey of experts - ICS specialists. In this case, each element of the matrix is defined as an arithmetic average of all assigned numerical values for a specific question.

Similarly, we define the values of the vector - line $\mathrm{X}_{0}$ using the expert analysis on a 3point scale. In this case, the technique of expert analysis may be as follows:

The questionnaire asks:

Assess the state of factors characterizing the prevailing environment situation in the region on a three-point scale (unsatisfactory, satisfactory, good) (tick the appropriate box with a plus sign):

$\mathbf{X}_{01}$ (The state of availability and training of ICS personnel in the unsat. satisf. good. region)

$\mathrm{X}_{02}$ (The state of budgetary financing of ICS in the region)

$X_{03}$ (The state of the regional policy of the management of the agroindustrial complex on the support of ICS)

$\mathbf{X}_{04}$ (The state of the presence of the competitive ICS environment in the region)

$X_{05}$ (The state of financial position of consumers of ICS in the region)

$\mathrm{X}_{06}$ (The state of consumer readiness to handle ICS in the region)

$\mathrm{X}_{\mathbf{0 7}}$ (ICS readiness status for various services)

As an example, we will make an expert assessment of the state of factors characterizing the current environmental situation in the region:

We compose the row- vector $\mathrm{X}_{0}$ on a 3-point scale:

1. Status of availability and training of ICS staff in the region:

a) unsatisfactory - 0 , 
b) satisfactory - 1 ,

c) good - 2,

We estimate $\mathrm{x} 01=2$

2. The state of budget financing ICS in the region:

a) unsatisfactory - 0 ,

b) satisfactory - 1 ,

c) good - 2,

We estimate $\mathrm{x}_{02}=1$

3. The state of the regional policy of the management of the agro-industrial complex in support of ICS

a) unsatisfactory - 0 ,

b) satisfactory -1 ,

c) good - 2,

We estimate $\mathrm{x}_{03}=1$

4. The state of the presence of the competitive ICS environment in the region:

a) unsatisfactory - 0 ,

b) satisfactory -1 ,

c) good - 2,

We estimate $\mathrm{x} 04=0$

5. The state of the financial situation of consumers of ICS services in the region:

a) unsatisfactory - 0 ,

b) satisfactory -1 ,

c) good - 2,

We estimate $\mathrm{x}_{05}=1$

6. State of consumer readiness for applying to ICS in the region:

a) unsatisfactory - 0 ,

b) satisfactory -1 ,

c) good - 2,

We estimate $\mathrm{x}_{06}=2$

7. The state of readiness of ICS for the provision of various services in the region:

a) unsatisfactory - 0 ,

b) satisfactory -1 ,

c) good - 2,

We estimate $\mathrm{x}_{07}=1$

As a result, we get the numeric row vector $\mathrm{X}_{0}(1 \times 7)$ : with the assigned values of the elements according to the answers of the expert:

$$
\mathrm{X} 0=\left[\begin{array}{lllllll}
2 & 1 & 1 & 0 & 1 & 2 & 1
\end{array}\right]
$$

After that, we define the objective function of conformity - $\mathrm{S}$ of the corresponding parameters of the organizational-legal form - $\mathrm{P}$, the factor situation occurring in the region $\mathrm{X}_{0}$.

Taking into account the given task which is to find the optimal form when organizing ICS, at least two approaches to quantify the objective function can be used.

The first approach is based on the criterion of maximally exceeding the form parameters estimates over the values of the factors or using the effect of maximally exceeding the form's potential possibilities over the "bar" of the factor situation occurring in the region - $\mathrm{X}_{0}$.

In formal form, the vector $\mathrm{D}$ (differential vector) and the compliance function $\mathrm{S}$ can be represented as follows: 


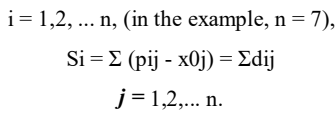

Criteria $\left.-S_{i}=\Sigma\left(p_{i j}-x_{0 j}\right)\right)=\Sigma d_{i j} \rightarrow \max$

$$
\mathrm{j}=1,2, \ldots . . n
$$

We calculate the vector $\mathrm{D}$ of the function $\mathrm{S}$ for our example:

$$
\begin{array}{lllllllllllllllllll}
\mathrm{X}_{0} & = & 2 & 1 & 1 & 0 & 1 & 2 & 1 & & & & & & & & & & \\
& & p_{1} & p_{2} & p_{3} & p_{4} & p_{5} & p_{6} & p_{7} & & d_{1} & d_{2} & d_{3} & d_{4} & d 5 & d_{6} & d_{7} & S_{i} & \text { grade } \\
& & \downarrow & \downarrow & \downarrow & \downarrow & \downarrow & \downarrow & \downarrow & & \downarrow & \downarrow & \downarrow & \downarrow & \downarrow & \downarrow & \downarrow & \downarrow & \downarrow \\
A_{1} & \rightarrow & 1 & 0 & 2 & 1 & 1 & 2 & 1 & \mid & -1 & -1 & 1 & 1 & 0 & 0 & 0 & |0| & 3 \\
A_{2} & \rightarrow & 2 & 1 & 1 & 1 & 0 & 2 & 2 & \mid & 0 & 0 & 0 & 1 & -1 & 0 & 1 & |1| & 2 \\
A_{3} & \rightarrow & 1 & 0 & 1 & 1 & 1 & 2 & 1 & \mid & -1 & -1 & 0 & 1 & 0 & 0 & 0 & |-1| & 4 \\
A_{4} & \rightarrow & 1 & 2 & 1 & 1 & 1 & 2 & 2 & \mid & -1 & 1 & 0 & 1 & 0 & 0 & 1 & |2| & 1 \\
A_{5} & \rightarrow & 0 & 0 & 0 & 1 & 2 & 0 & 0 & \mid & -2 & -1 & -1 & 1 & 1 & -2 & -1 & |-5| & 5 \\
A_{6} & \rightarrow & 0 & 0 & 0 & 0 & 0 & 2 & 0 & \mid & -2 & -1 & -1 & 0 & -1 & 0 & -1 & |-6| & 6
\end{array}
$$

The grade value is determined by the place that was received by the organizational and legal form with the highest value of the compliance function.

The obtained result shows that under the prevailing conditions in the region it is most preferable to establish departments for the implementation of agrotechnologies of scientific research institutes; training centers for farmers in the university; or in the form of consulting centers at the Farmers Council.

The second approach is based on the criteria of identifying the most positive properties (parameters) of organizational and legal forms by certain factors of the current situation in the region or using the effect of "enhancing" the potential of the form in certain situations of the external environment $\mathrm{X}_{0}$.

In formal form, the compliance function $\mathrm{S}$ can be represented as follows:

$$
\mathrm{S}=\mathrm{P} * \mathrm{X}_{0}=\left[\mathrm{S}_{\mathrm{i}}\right]
$$

in which $\mathrm{P}$ is the matrix of parameters of various forms (dimension $7 \mathrm{x} \mathrm{n}$, in the case of the considered example $-7 \times 6) ; X_{0}$ is the vector of environmental factors represented as a column vector $\left[\mathrm{x}_{0 \mathrm{i}}\right]$ with $\mathrm{i}=1,2 \ldots \mathrm{n}$ (dimension $\mathrm{n} \times 1$, in the case of the considered example, $7 \times 1) ; S_{i}$ is the column vector of the compliance function for each form. $i=1,2, \ldots$ 6.

\section{Criteria $-\mathrm{S}_{\mathbf{i}} \rightarrow \max$}

We calculate the vector $\mathrm{S}$ for our example:

$\begin{array}{lllllllllllll} & & p_{1} & p_{2} & p_{3} & p_{4} & p_{5} & p_{6} & p_{7} & X_{0} & & S_{i} & \begin{array}{l}\text { gra } \\ \text { de }\end{array} \\ & & \downarrow & \downarrow & \downarrow & \downarrow & \downarrow & \downarrow & \downarrow & \downarrow & & \downarrow & \downarrow \\ A_{1} & \rightarrow & 1 & 0 & 2 & 1 & 1 & 2 & 1 & |2| & 2 * 1+1 * 0+1 * 2+0 * 1+1 * 1+2 * 2+1 * 1= & 10 & 3 \\ A_{2} & \rightarrow & 2 & 1 & 1 & 1 & 0 & 2 & 2 & |1| & 2 * 2+1 * 1+1 * 1+0 * 1+1 * 0+2 * 2+1 * 2= & 12 & 2 \\ A_{3} & \rightarrow & 1 & 0 & 1 & 1 & 1 & 2 & 1 & |1| & 2 * 1+1 * 0+1 * 1+0 * 1+1 * 1+2 * 2+1 * 1= & 9 & 4 \\ A_{4} & \rightarrow & 1 & 2 & 1 & 1 & 1 & 2 & 2 & |0| & 2 * 1+1 * 2+1 * 1+0 * 1+1 * 1+2 * 2+1 * 2= & 12 & 1 \\ A_{5} & \rightarrow & 0 & 0 & 0 & 1 & 2 & 0 & 0 & |1| & 2 * 0+1 * 0+1 * 0+0 * 1+1 * 2+2 * 0+1 * 0= & 2 & 6 \\ A_{6} & \rightarrow & 0 & 0 & 0 & 0 & 0 & 2 & 0 & |2| & 2 * 0+1 * 0+1 * 0+0 * 0+1 * 0+2 * 2+1 * 0= & 4 & 5\end{array}$

The grade value is determined by the place that was received by the organizational-legal form with the highest value of the compliance function.

The obtained result in this case shows that, under the prevailing conditions in the region, it is most preferable to establish departments for the implementation of 
agrotechnologies of scientific research institutes; training centers for farmers in the university; or in the form of consulting centers at the Council of Farmers.

Taking into account the two-step approach to the choice of the optimal form, it is advisable to combine the criterion scores (grades) into a single total score by adding the obtained values of the grades:

$$
\begin{gathered}
\mathrm{Ri}=\mathrm{Ri} 1+\mathrm{Ri} 2 \\
\mathrm{i}=1,2, \ldots . \mathrm{m},
\end{gathered}
$$

in which $R_{i}$ is the total grade of the $\mathrm{i}$ - form; $\mathrm{R}_{\mathrm{il}}$ is the grade of the $\mathrm{i}$ - form obtained as a result of the first approach of the criterion choice; and, $\mathrm{R}_{\mathrm{i} 2}$ is the grade of the $\mathrm{i}$ - form obtained as a result of the second approach of criterion choice.

Then the criterion of optimality of choice will be: $\mathrm{Ri} \rightarrow \min$

For the example considered above, the combination of criterion estimates, the summation of grades shows the following:

$\begin{array}{lll}\boldsymbol{R}_{1} & =3+3=6 & \text { place } \\ \boldsymbol{R}_{2} & =2+2=4 & 3 \\ \boldsymbol{R}_{3} & =4+4=8 & 2 \\ \boldsymbol{R}_{4} & =1+1=2 & 4 \\ \boldsymbol{R}_{5} & =5+6=11 & 1 \\ \boldsymbol{R}_{6} & =6+5=11 & 6\end{array}$

Thus, the combined criterion shows that under the prevailing conditions in the region it is most preferable to establish departments for the implementation of agrotechnologies of scientific research institutes; training centers for farmers in the university; or in the form of consulting centers at the Council of Farmers, which confirms the results of the second approach of criterion of choice assessment.

According to the second task of the research, the choice of the optimal organizational and legal form of already operating ICS should be carried out in such a way that the selected organizational and legal form would minimize the possible risks of the production function of the ICS to the maximum extent.

The fact is that the improvement of the external environment in the region (raising the level of budget financing, the proficiency of specialists, increasing the attention of authorities to the problems of ICS, etc.), i.e. an increase in the values of the estimated environmental factors will, in general, have a positive impact on the activity of ICS of any form. The degree of influence of these factors on the ICS will be different, but in any case, positive.

In case of deterioration of environment conditions in the region (for example, first of all, a decrease in the level of budget financing or its complete cessation), i.e. a decrease in the values of the estimated factors of the external environment may lead to the risk of partial or complete non-fulfillment of the production function of the ICS (for example, of the bankruptcy of the service).

In this case, the problem of choosing a stable form of the organization of ICS in the process of its functioning in a changing dynamic state of the external environment can become the main one when making appropriate decisions to improve the effectiveness of regional ICS.

A specific objective function can be a certain complex function of influence $(\Psi)$ of factors $\mathrm{X}$ on the production function $\mathrm{F}(\mathrm{A}, \mathrm{P}, \mathrm{X})$, and the criterion is the minimization of this function of influence (or the max stability function). The influence function for a specific organizational and legal form can be represented as a dependence $\Psi$ (A, X), in which $\mathrm{A}$ is a variety of different forms; $\mathrm{X}$ is a vector-string of environment factors $\left[\mathrm{x}_{0 \mathrm{i}}\right]$ with $\mathrm{i}=1,2 \ldots \mathrm{n}$, affecting the ICS activity. 
It should be mentioned that the influence of factors on the production function can be assessed taking into account two approaches. The first takes into account the relative strength of the influence of these factors among themselves on any form, and the second the relative degree of influence of factors on specific forms of ICS, i.e. it takes into account the sensitivity of a particular form to changes in various factors. For example, the factor the degree of budget financing has a much stronger impact on the activities of the ICS than the factor - the presence of a competitive environment. On the other hand, the factor - the degree of budget financing for ICS in the form of a private firm has no effect, unlike the factor - the presence of a competitive environment, i.e. the form of ICS in the form of a private firm is more sensitive to a factor - the presence of a competitive environment and less sensitive to a factor - the degree of budget financing.

For example, we consider the following factors, which may have a certain impact on the ICS activity with various forms, which are described in the last example (set A):

$\mathrm{x}_{1}$ - availability and training of ICS personnel,

$\mathrm{x}_{2}$ - the degree of budget financing,

$\mathrm{x}_{3}$ - regional policy of the agro-industrial complex management on the support of ICS,

$\mathrm{x}_{4}$ - the presence of a competitive ICS environment,

$\mathrm{x}_{5}$ - financial status of consumers of ICS.

In this case, the dimension of the vector is $1 \times 5$.

In order to assess the influence of various factors on the production function of ICS, at first, it is necessary to compare the degree of influence (or strength) of these factors among themselves, which can be done by grading the strength of the factors with an expert (expert group). The factors according to the degree of influence can be represented by the expert in the form of the following relations $\mathrm{x}_{1}>\mathrm{x}_{2}>\mathrm{x}_{\mathrm{i}}>\ldots>\mathrm{x}_{\mathrm{n}}$, in which the sign $>$ means the ratio of preference (the factor $\mathrm{x}_{1}$ influences more than the factor $\mathrm{x} 2$ ); $\mathrm{n}$ is the number of factors considered.

In the simplest cases, the transition to quantitative estimates can be carried out by replacing the grade scale with an absolute scale of numbers.

The factor that received the 1 grade according to the degree of greatest influence acquires the maximum quantitative estimate, $n$, the factor that receives 2 nd grade acquires a quantitative estimate of $n-1$, etc. The last factor gets a quality estimate $=1$.

In the example, the most influential factor in the grading receives an estimate $=5$, and the least influencing one will receive an estimate $=1$.

The second approach takes into account the sensitivity of the organizational and legal form to changes in each factor, which can also be graded by expert. In this case, the expert records the relations of preference for the i- factor and various organizational and legal forms (OLF), for example, $\mathrm{OLF}_{1}>\mathrm{OLF}_{2}>\ldots>\mathrm{OLF}_{\mathrm{m}}$,

Here, the preference relation is read like "production function $\mathrm{OLF}_{1}$ is more sensitive to changes in factor $\mathrm{x}_{\mathrm{i}}$ than production function $\mathrm{OLF}_{2}$ "; and, $\mathrm{m}-$ the number of considered legal forms.

In this case, the transition to quantitative estimates can also be carried out by replacing the grade scale with an absolute scale of numbers.

We denote these numbers for the first approach, i.e. the preference coefficient for the degree of influence of various factors on all OLFs is $\alpha \mathrm{i}$, and for the second approach, i.e. the coefficient of preference for the influence of the $i$ - factor on the $j$ - OLF among the other OLFs $-\beta i j$, where $i=1, \ldots, n, j=1, \ldots, m$.

Then an expert quantitative estimate of the degree of influence of the $i$ - factor in the $j$ legal form can be represented as the following expression:

$$
\begin{gathered}
\Psi i j(A j, X i)=\alpha i \beta i j \\
i=1,2, \ldots . n
\end{gathered}
$$

The function of the complex influence of $n$ factors on the $\mathrm{j}$ OLF: 
Criterion for choosing OLF:

$$
\begin{gathered}
\Psi \mathrm{i}(\mathrm{Aj}, \mathrm{Xi})=\Sigma \alpha \mathrm{i} \beta \mathrm{ij} \\
\mathrm{i}=1,2, \ldots . \mathrm{n}
\end{gathered}
$$

$$
\Psi_{\mathrm{i}}\left(\mathrm{A}_{\mathrm{j}}, \mathrm{X}_{\mathrm{i}}\right)=\Sigma \alpha_{\mathrm{i}} \beta_{\mathrm{ij}} \rightarrow \min
$$

We consider the proposed method in an example. In this case we will consider the above number of legal forms - A, and many factors - X.

In this case, the technique of expert analysis may be as follows:

To assess the degree of influence (or strength) of factors among themselves, the question for examination is asked:

Arrange (grade) in order, all the factors according to the degree of their greatest influence on the activities of ICS (greater degree of influence - greater sequence number):

$\mathrm{x}_{1-} \quad$ availability and training of ICS

degree of budget financing

$\mathrm{x}^{-}-\quad$ regional policy of the agro-industrial complex management in support of ICS - 3

$\mathrm{x}_{4}-\quad$ availability of competitive ICS environment

$\mathrm{X}_{5}-\quad$ financial status of consumers of ICS services

Thus, moving on to the quantitative scale, we can write

$$
\alpha_{1}=5, \alpha_{2}=4, \alpha_{3}=3, \alpha_{4}=1, \alpha_{5}=2 .
$$

Further in the questionnaire for examination taking into account the second approach the following questions are asked:

1. Arrange (grade), in order, the various forms according to the degree of the greatest sensitivity to a change in factor $\mathrm{x}_{\mathrm{i}}$ - the presence and preparation of ICS frames (a greater degree of sensitivity - a higher ordinal number):

$\mathrm{A}_{1-} \quad$ consulting centers at the Council of Farmers

$\mathrm{A}_{2-} \quad$ training centers for farmers in the university

$\mathrm{A}_{3}-$ information and consultation centers at the Chamber of Commerce and Industry - 3

A4- departments of the implementation of agricultural technologies of research -2 institutes

$\mathrm{A}_{5-} \quad$ extension components of projects of international organizations -5

$\mathrm{A}_{6^{-}} \quad$ private firms providing information and consulting services - 6

2. Arrange (grade) in order the various forms according to the degree of the greatest sensitivity to a change in factor $\mathrm{x}_{2}$ - the degree of budget financing of the ICS (a large degree of sensitivity is the larger sequence number):

$\mathrm{A}_{1-} \quad$ consulting centers at the Council of Farmers

$\mathrm{A}_{2-}$ training centers for farmers in the university -5

$\mathrm{A}_{3}-$ information and consultation centers at the Chamber of Commerce and - 3 Industry

A4- departments of the implementation of agricultural technologies of research -6 institutes

A5- extension components of international organizations projects $\quad-2$

A6- $\quad$ private firms providing information and consulting services -1

3. Arrange (grade) all organizational and legal forms in order according to the degree of sensitivity to the change of factor $\mathrm{X}_{3}$ - regional policy of the agricultural production complex management on ICS support: (greater degree of sensitivity - greater sequence number):

$\mathrm{A}_{1-} \quad$ consulting centers at the Council of Farmers

$\mathrm{A}_{2-} \quad$ training centers for farmers in the university -4

$\mathrm{A}_{3-} \quad$ information and consultation centers at the CCI -5

$\mathrm{A}_{4-}$ departments of the introduction of agricultural technologies of research - 3 institutes 
A5- extension components of international organizations projects -1

$\mathrm{A}_{6^{-}} \quad$ private firms providing information and consulting services

4. Arrange (grade) all organizational and legal forms in order according to the degree of sensitivity to the change of factor $\mathrm{X}_{4}$ - availability of the competitive ICS environment (a greater degree of sensitivity - a greater serial number):

$\mathrm{A}_{1-} \quad$ consulting centers at the Council of Farmers

$\mathrm{B}_{4 \mathrm{j}}$

$\mathrm{A}_{2-} \quad$ training centers for farmers in the university

$-5$

$\mathrm{A}_{3-}$ information and consultation centers at the Chamber of Commerce and Industry

$-3$

A4- departments of the implementation of agricultural technology research institutes

$-4$

$-2$

A5- extension components of projects of international organizations

$\mathrm{A}_{6^{-}}$private firms providing information and consulting services

5. Arrange (grade) all organizational and legal forms in order according to the degree of sensitivity to a change in factor $\mathrm{X}_{5}$ - financial status of consumers of ICS services: (greater degree of sensitivity - greater sequence number):

$\mathrm{A}_{1-}$ consulting centers at the Council of Farmers

$\mathrm{A}_{2-}$ training centers for farmers in the university

$\mathrm{A}_{3-}$ information and consultation centers at the Chamber of Commerce and - 4 Industry

A4- departments of the implementation of agricultural technology research - 2 institutes

$\mathrm{A}_{5-} \quad$ extension components of international organizations projects

$\mathrm{A}_{6-} \quad$ private firms providing information and consulting services

Based on the data obtained, we will make up a matrix for calculating the influence function:

\begin{tabular}{|c|c|c|c|c|c|c|c|c|c|c|}
\hline & & $\beta_{1}$ & $\beta_{2}$ & $\beta_{3}$ & $\beta_{4}$ & $\beta_{5}$ & $\alpha_{j}$ & & $S_{i}$ & grade \\
\hline & & $\downarrow$ & $\downarrow$ & $\downarrow$ & $\downarrow$ & $\downarrow$ & $\downarrow$ & & $\downarrow$ & $\downarrow$ \\
\hline$A_{1}$ & $\rightarrow$ & 4 & 4 & 6 & 5 & 5 & $|5|$ & $5 * 4+4 * 4+3 * 6+1 * 5+2 * 5=$ & 69 & 6 \\
\hline$A_{2}$ & $\rightarrow$ & 1 & 5 & 4 & 3 & 3 & $4 \mid$ & $5 * 1+4 * 5+3 * 4+1 * 3+2 * 3=$ & 46 & 2 \\
\hline$A_{3}$ & $\rightarrow$ & 3 & 3 & 5 & 4 & 4 & $|3|$ & $5 * 3+4 * 3+3 * 5+1 * 4+2 * 4=$ & 54 & 4 \\
\hline$A_{4}$ & $\rightarrow$ & 2 & 6 & 3 & 2 & 2 & $|1|$ & $5 * 2+4 * 6+3 * 3+1 * 2+2 * 2=$ & 49 & 3 \\
\hline$A_{5}$ & $\rightarrow$ & 5 & 2 & 1 & 1 & 1 & $|2|$ & $5 * 5+4 * 2+3 * 1+1 * 1+2 * 1=$ & 39 & 1 \\
\hline$A_{6}$ & $\rightarrow$ & 6 & 1 & 2 & 6 & 6 & $|6|$ & $5 * 6+4 * 1+3 * 2+1 * 6+2 * 6=$ & 58 & 5 \\
\hline
\end{tabular}

The obtained result in this case shows that with the functioning of the ICS in changing factor conditions, the most stable and, therefore, the preferred organizational and legal form in a particular region is its operation as part of the extension components of international organizations projects; either in the composition of farmer training centers at universities, or in the form of departments for the implementation of agrotechnologies at research institutes.

The choice of the optimal form for the integrated estimation of the creation and functioning of the regional ICS is advisable to carry out taking into account the solution of the first two tasks and use the obtained criteria estimates (grades) for their addition to a single total estimate:

$$
\begin{gathered}
\operatorname{Ri}(3)=\operatorname{Ri}(1)+\operatorname{Ri}(2) \\
i=1,2, \ldots . m .
\end{gathered}
$$

in which $R_{i}$ (3) is the total rank of the $i$ - form with an integrated estimate; $R_{i}(1)$ is the grade of the $i$ - form, obtained as a result of solving the first problem; and, $R_{i}(2)$ is the grade of the form obtained by solving the second problem.

Then the general, complex criterion of optimality of choice will be:

$$
\mathrm{Ri}(3) \rightarrow \min \text {. }
$$

For the example considered above, the combination of criterion estimates- summation of grades shows the following: 


$\begin{array}{llllllll} & \mathrm{R}_{\mathrm{i}} & (1) & \mathrm{R}_{\mathrm{i}} & (2) & \mathrm{R}_{\mathrm{i}} & (3) & \text { place } \\ & & \downarrow & & \downarrow & & \downarrow & \downarrow \\ \mathrm{R} 1 & = & 3 & + & 6 & = & 9 & 5 \\ \mathrm{R} 2 & = & 2 & + & 2 & = & 4 & 2 \\ \mathrm{R} 3 & = & 4 & + & 4 & = & 8 & 4 \\ \mathrm{R} 4 & = & 1 & + & 3 & = & 4 & 1 \\ \mathrm{R} 5 & = & 6 & + & 1 & = & 7 & 3 \\ \mathrm{R} 6 & = & 5 & + & 5 & = & 10 & 6\end{array}$

Consequently, the general integrated criterion shows that in the region it is most preferable to establish a regional ICS as part of the implementation of agricultural technologies of institutes, either as part of farmers training centers at universities, or as part of extension components of international organizations projects.

\section{Conclusions}

Thus, the scientific and methodological approaches for choosing the optimal organizational and legal form of ICS, based on expert methods for assessing the properties of various forms of service organization and assessing the factors of the regional environment, can serve as a basis for creating new regional ICS and preparing proposals about the expediency of changing the organizational and legal form of already operating ICS.

\section{References}

1. J.C. Aker, Agricultural Economics, 42, 631-647 (2011)

2. F.C. Anaeto, C.C. Asiabaka, F.N Nnadi, J.O. Ajaero, F.O. Ugwoke, M.U Ukpongson, A.E. Onweagba, Journal of Agriculture Research, 1(6), 180-185 (2012)

3. N.S. Dekhkanova, International Journal for Innovative Research in Multidisciplinary Field, 5(11), 52-57 (2019)

4. N.S. Dekhkanova, J. Rozikov, O. Tonkix, F. Yakubov, International Journal Of Research Culture Society, 4(1), 128-135 (2020)

5. F.R. Galimova, N.S. Dekhkanova, International Scientific and Practical Conference, 123-126 (2015)

6. F.R. Galimova, International Journal Of Research Culture Society, 4(1), 121-127 (2020)

7. K. Knickel, G. Brunori, S. Rand, J. Proost, The Journal of Agricultural Education and Extension, 15, 131-146 (2009)

8. A. Knierim, P. Labarthe, C. Laurent, K. Prager, J. Kania, L. Madureira, T. Ndah, Journal of Rural Studies, 55, 45-58 (2017)

9. P. Labarthe, Journal of Environmental Management, 90, S193-S202 (2019)

10. G.K. Narinbaeva, F.R. Islamov, S.A. Davlatov, G.B. Ergashev, Journal of Science and Healthcare Exploration (JSHE), 1(6), 6 (2019)

11. I. Rustamova, Indo Global Journal of Commerce and Economics, 156-160 (2017)

12. I.B. Rustamova, Collection of international conference of Tavria State AgroTechnological University, 4, 153-162 (2009)

13. I. B. Rustamova, Journal "Economic Bulletin of Uzbekistan", 5, 79-82 (2013)

14. I.B. Rustamova, F. R. Galimova, Actual science: International scientific journal, Volgograd: SIC “Absolute”, 4(9), 12-16 (2018) 
15. I.B. Rustamova, F.R. Galimova, Agroeconomics: Scientific and Practical Agroeconomic Journal, 57-59 (2019)

16. B. Rustamova, F.R. Galimova, Actual science: International scientific journal, Volgograd: Research Center "Absolute", 1(18), 51-53 (2019)

17. G.A. Samatov, F.R. Galimova, International scientific and practical conference, SouthWestern State University, 151-155 (2013)

18. G.K. Narinbaeva, F.R. Islamov, S.A. Davlatov, G.B. Ergashev, Journal of Science and Healthcare Exploration (JSHE), 1(6), 6 (2019)

19. B.Yu. Menglikulov, D.U. Mamadiyarov, Sh. Ergasheva, Sh. Normuminovich, International Journal of Recent Technology and Engineering (IJRTE), 8(4), 3 (2019) 